\title{
On Chinese College Students' Suicide: Characteristics, Prevention and Crisis Intervention
}

\author{
Xiaohong Li \\ School of Life Science \& College of Biotechnology, Southwest University \\ Chongqing 400716, China
}

Received: June 25, 2012

Accepted: August 5, 2012

Online Published: August 13, 2012

doi:10.5430/ijhe.v1n2p103

URL: http://dx.doi.org/10.5430/ijhe.v1n2p103

Funds: This paper was the research achievement of A Study on Coordination of College Students' Study and Life Planning funded by 2010 Social and Humanity Research Fund of the Ministry of Education (10JDSZ3077), also the achievement of A Study on Ideological Safety Problem at Chinese Tertiary Institutions (SWU1209385) supported by Southwest University's Central Tertiary Basic Research Funds.

\begin{abstract}
Nowadays, some characteristics have been detected among Chinese students' suicide including an increasing rate, obvious differences in different grades and genders, relatively integrated suicide methods and a regular time pattern for suicide as well. The principle of selection at registration, dynamic renewal and classified precaution should be followed to prevent aggregation. In addition, all students especially those with the personality liable to commit suicide should be given systematic education on psychological health and those with mental disease or depression should be offered medical and psychological treatment. Crisis intervention should also be attached importance to for those intend to commit suicide and even after their suicide.
\end{abstract}

Keywords: College students, Suicide, Characteristics, Prevention, Crisis intervention

\section{Introduction}

Along with the development of Chinese society, unprecedented changes have taken place in college students' values, psychological emotions and modes of thinking, as well as in China's overall social structure and traditional personalities. As a result, new characteristics arise in college students' suicides. Suicide intervention refers to offering prompt assistance and guidance to those people with strong intentions for suicide in order to avoid it. Suicide intervention is intended to relieve the client's intention for suicide as well as to offer guidance for future psychological treatment. Due to the increasingly serious suicide among college students in recent years, it is of particular value to explore into its characteristics and take effective measures for prevention and crisis intervention.

\section{The Characteristics of Chinese College Students' Suicide}

\subsection{Rising Suicide Rate}

A rising suicide rate has become a global trend. China has witnessed the serious situation of its college students' suicides. As is shown in relevant materials, "the suicide rate among college students is 2 to 4 times that among others of their age and it is getting worse nowadays. Obviously, college students have formed a high-risky group of suicide" (Zhai, 1997). In 2003, Zhixia Chen and her colleagues, from Sociology Department of Huazhong University of Science and Technology, conducted a questionnaire survey on college students' attitudes toward suicide among 1010 college students in the way of stratified sampling, which showed that altogether $10.7 \%$ of the surveyed students had the intention for suicide (Chen, 2004).

In the recent years, there has been an increase in suicide among college students. As is reported by media, there were 27 cases of college students committing suicide in 2002 and then rose to 68, 116 and even 130 in 2004, 2005 and 2006 respectively. It is even worse in the past two years (Wang, 2009). As for its reasons, first, there have been an increasing number of college students with the expansion of college scale and the generalization of higher education. Along with such an increase, the number of college students who commit suicide has risen as well. Second, the dramatic changes in the social environment and the current stage of reform have led to more severe social conflicts. Such a combination between complex external environment and individual students' fragile psychology may increase 
the possibility of suicide among them. Third, the currently fierce competition has also strengthened college students' stress from employment and school work, hence making some of them psychologically overburdened.

\subsection{Differences in Grade and Gender Groups}

As far as the grade is concerned, a majority of college students who commit suicide are freshmen and seniors. As for the motivation for suicide, those freshmen who commit suicide are mostly suffering from some problems related to adjustment to their college life, such as the change in environment, the transfer of roles, study problems and interpersonal relationships. Seniors are faced more with some problems related to their future life such as material life, the postgraduate entrance exam, employment and so on. Comparatively, there is even a greater difference shown in different genders. Actually, there is a regular distribution of college suicides in gender: Females have a higher suicide rate compared with males. It is shown in statistics that the number of female students who commit suicide is three time that of males. Female students account for over $65 \%$ of the total, especially those who are disappointed in love. In addition, males have a higher complete suicide rate than females (Wang, 2007). Most scholars relate this gender difference to female students' sensitive feelings, strong dependence, lacking sense of self-protection and frequent frustrated feelings. In spite of a relatively small number, male suicides, once having the intention to commit suicide, tend to adopt intensive methods completely, hence having an obviously higher complete suicide rate.

\subsection{Relatively Integrated Suicide Methods}

It is shown that college students tend to take the following methods for suicide: hanging themselves, falling off a building, drowning and taking poison. According to our survey, there is currently an increasing proportion of falling off a building among college students perhaps because it has a high fatality rate and is easy to be conducted. Most students choose teaching or dormitory building or even the same place in some universities. For instance, in a Chinese university, in students in three cases of suicide used this way in all the five ones, in which two even happened in the same building. There has been no conclusion on whether this is out of preference or emulation.

\subsection{Regular Periods for College Students'Suicide}

College students tend to commit suicide in spring and autumn. According to relevant surveys, such cases are grouped from April to June and from September to October, during which $31.3 \%$ of the total really take place (Guo, 2004). It is caused by seasonal characteristics, leading to people's depression and empty feelings. In addition, college students tend to have a periodical summary and reflection on some tough problems before and after their summer or winter vacations in order to seek for ways and countermeasures. Once these ways and countermeasures are ineffective, they tend to suffer from psychorrhexis and even commit suicide eventually. Therefore, such periods put some students at risk.

\section{Principles for Prevention and Crisis Intervention of College Students' Suicide}

\subsection{Screening, Dynamic Renewal and Classified Prevention}

Due to heredity, different social and family environments, college students have formed different physical and psychological conditions and personality characteristics, exerting diverse influences on college students' suicide intentions and actions. As a result, newcomers should be assessed on their physical and psychological health conditions. Besides, the information should be renewed constantly during their whole college life to establish dynamic psychological documents to keep track of relevant changes. Generally, college students go through the process of forming the intention for suicide, struggling and finally taking actions. Although these stages are not necessarily consecutive, intention is a strong risk factor for death in suicide (Nordstrom, 1995). It is revealed in some cases and analysis on the factors influencing college students' suicide that some students' personality or mental diseases caused by their previous living environments are the risk factors for suicide. Accordingly, students can be grouped and corresponding preventive and interfering measures can be taken.

The combination of psychological measurement and behavior observation is adopted to monitor college students' physical and psychological health and personality characteristics.

Currently, in the survey on physical and psychological health as well as personality are widely adopted UPI, SCL-90, Cattell's Sixteen Personality Factor Questionnaire and Eysenck Personality Questionnaire. UPI, coming from Japan, is used to have siftings among college newcomers about their psychological problems, in which the $25^{\text {th }}$ question on the intention to commit suicide serves as an evidence when judging students' intention for suicide. In addition, the investigation table assesses college students' potential split personality and depression. SCL-90, of higher validity and reliability through amendment, includes 90 items such as somatization, interpersonal relationship, depression, obsession, anxiety, mental disorder and so on. The 25th question - "intend to end his life" - helps to form a basic 
judgment on split personality and depression. All college students, no matter with or without physical and psychological problems, should be educated systematically on the views on life, responsibility and values as well as be trained and guided in adaptability, academic learning, interpersonal relationship and employment. As for those students with certain personality characteristics or mental disorder, proper psychological consultation and treatment are of particular importance. For those with suicide intentions, every effort should be made to conduct timely crisis intervention and post-crisis intervention.

\subsection{Preventing Polymerization}

With different external factors, internal factors and life events influencing college students' suicide, case study shows that only one single factor cannot explain the real reasons for suicide. Actually, suicide generally results from the joint effects of external factors, internal factors as well as life events. Therefore, we should avoid such a joint effect, that is, polymerization, to happen, including preventing suicide intention, preventing such an intention being converted into action and preventing the emulation of suicide. With these principles, some specific measures can be taken to prevent suicide happening, including offering education on life, responsibility and frustration to improve students' psychological quality and eliminate preconditions for their suicide intention, providing those highly-risky students with specific assistance to avoid the joint function of different factors. In addition, when reporting college students' suicide, the media should blame it as well as show regret in order to discourage others from imitating those victims, hence avoiding the spread of suicide.

\section{Specific Measures for the Prevention and Crisis Intervention of College Students' Suicide}

\subsection{Conducting Systematic Psychological Health Education on All Students Especially Those with Suicide Personality Characteristics}

For a long run, China has been lying in an exam-oriented education system. Due to too much importance attached to the convey of knowledge while too little to the training and improvement of psychological quality, students have poor psychological quality, lacking proper self-recognition, frustration and pressure resistance and the capacity for tackling with difficulties, hence leading to unhealthy physical and psychological conditions and even pessimistic emotions. As is revealed in a survey on psychological health of freshmen in a university conducted by Qin Lu, college students have declining psychological health conditions in the recent years ( $\mathrm{Lu}, 2010)$. It is widely acknowledged that the majority of those suicide victims have more or less psychological problems. Therefore, proper education can effectively prevent college students' suicide actions.

First of all, in staff allocation and institution setting, special institutions for psychological consultation and psychological health education should be established with the staff specialized in psychological health education together with others such as counselors, teachers in charge of classes, dormitory supervisors and student leaders. these people, along with students, should be trained regularly on relevant psychological health and suicide prevention knowledge. In spite of some existing institutions at present, their staff is not professional and effective enough to offer actual assistance to students. It is worth noting that solving these problems is a precondition for the effective implementation of psychological health education.

Besides, psychological health education mainly involves the basic knowledge on psychological health, college students' physical and psychological characteristics and some relevant contents on life, responsibility and frustration. Life education means guiding students to form right recognition about people's value, life and to understand the true significance of life as well as developing their humanistic spirit and enabling them to lead a modern civilized life (Liu, 2000). When conducting life education among college students, the basic idea should be embedded throughout the whole process, helping students to realize the significance of their lives and then to accomplish their value as well as guiding students to cherish their lives and avoiding suicide actions and intentions (Chu, 2007). As a result, psychological health education for college students based on suicide prevention should cover the contents of responsibility education. In addition to caring about themselves and developing the sense of responsibility for themselves, they should also be educated to have responsibility for their families, friends and even the whole society and to deeply realize that suicide is such an immoral and irresponsible behavior that it should be blamed in any circumstance. Education on frustration is also indispensable. Students should form the right attitudes toward frustration, including the positive and negative effects of frustration, creating reasonable frustration situations and improving students' resistant ability against frustrations with proper guidance. In this way, frustration may become a treasure in their life instead of an obstacle.

Third, psychological health class can be mainly relied on along with educational practice. During the course, some actual problems or psychological troubles in students' daily life should be relied on, combined with the 
characteristics for college students' psychological and physical development, to educate students at different stages with different emphasis. As for freshmen, for instance, some instructive courses on adaptability and interpersonal relationship should be set up to help students to be quickly adapted to their college life and shift their roles. In addition, psychological instruction on their learning is also indispensable to help them to establish definite learning objectives, to realize the significant differences between college learning and high school learning. In this way, they are more likely to grasp good learning methods and have better ability for self-control and self-arrangement. Career planning course is effective to help students to establish right career objectives and learn about the society's demands, to urge them to improve their quality to fulfill social demands. Especially for seniors facing graduation, employment instruction courses should be offered to help them establish right employment ideas and employment information should be accumulated through diverse channels and be delivered to students immediately, hence expanding their employment channels. Life frustration education, involving students' own experiences, should be involved in every corner of daily teaching and learning activities and colorful social practice. Through their own experiences, students come to appreciate the significance of life, to realize their value, to have stronger courage and confidence when faced with frustrations and to form sound personalities and healthy minds.

\subsection{Conducting Medical and Psychological Treatment on Students with Mental Disease or Depression}

As far as the students who have diagnosed mental diseases or depression through psychological measurement and behavior observation, professional psychological health institutions or experts should be involved in analyzing their psychological health conditions. Based on the analysis and discussion with their parents, universities can make wise decisions (Meng, 2002). Those with slight symptoms can still stay at school with necessary psychological and medical treatment by professionals of psychological consultation institutions. In addition, parents and classmates' concerns are important for offering necessary support and giving them warmth they need. For those with serious symptoms, who tend to be ignorant of their own illness and ignore necessary medicines, or have strong desire for suicide in the case of serious depression, they should be sent back home or to professional institutions for treatment in order to prevent suicide from happening.

\subsection{Crisis Intervention with Students with Suicide Intention}

In the case of those with suicide intention, their lives should be protected first of all, which is the core of crisis intervention. Classmates or close friends can stay with them in turn to avoid their risky actions. In addition, proper communication serves as psychological support to help them to develop love for life (Cui, 2006). Second, professional consultants can talk with these students' classmates, friends and parents about them, including their personality, past learning experience, interpersonal relationship, feelings, whether they have experienced major events, whether they have abnormal emotions or odd actions, their main concerns and so on. Finally at the real psychological intervention stage, professional consultants listen to students' account and have talk with them with patience and empathy to form an evaluation of the seriousness of the problem, their unreasonable ideas and some actual problems and then work out plans and methods for treatment. The school should cooperate with professional consultants to offer actual help to the students with suicide intention, such as permitting remissions on their tuition, extending the deadline for tuition or offering subsidies to relieve some poor students' living stress. In addition, according to the treatment progress, professional consultants should adjust treatment to help students to change wrong and unreasonable ides, to establish proper cognitions, to have strengthened responsibility for family and society and to improve their resistance and confidence against suicide intention.

\subsection{Crisis Intervention after Suicide}

Once some suicides really happen due to some unexpected factors, support and intervention should be implemented at the same time. First, psychological restoration on those who didn't complete suicide should be attached great importance to. Many victims in such a situation are over-sensitive to the surroundings and people's attitudes shortly after their survival. Therefore, we should be calm, caring and non-prejudiced, making no moral judgment on their suicide and values during the crisis period in order to avoid resistance and hostility. At the initial period, suggestion, guarantee, outlet for some negative feelings, changes in surroundings and sedative can be employed to restore the victims' emotion to the pre-crisis level. Meanwhile, a psychological support system composed of society, school and family should be established to help these students develop love for life as well as responsibility for society and family with great care and assistance by their relatives, friends, teachers and classmates. After some time, some assistance can be given to them to face up with crisis and overcome difficulties in daily life. According to relevant surveys, $90 \%$ of those who once committed suicide may give up such a ridiculous idea after effective intervention (Shen, 2004). In addition, once death is caused by suicide, the relevant student group's psychology should be repaired as well. One complete suicide may affect at least six people psychologically and those who experience or 
witness the scene may suffer from post-traumatic stress disorder (PTSD).

Schneidman developed an intervention technology in psychological anatomy, that is, professional consultants can hold instruction lectures on psychological sadness which encourage some students close to the victim to look back on his psychological development, to reflect on the reasons for his suicide and to think over this issue seriously. Through analysis, reflection, mourning and relaxation technology, students will form a proper recognition of suicide, be relieved of stress and fear, get out of the crisis filled with shock, sadness, regret and depression, hence gaining more experiences as well as restoring their study and life.

\section{Conclusion}

Since life is a unique gift we are endowed, nobody has the right to disrespect it. The unification of rights and obligations with a life's birth cannot be broken by anybody as well. Everyone must value his life due to its preciousness and uniqueness, face up to his fate and spare no effort to create happy life during the course of pursuing the significance of life and exploring its value. It is certain that suicide is a wrong choice as well as an irresponsible behavior for the society and families. In spite of the small proportion of suicides among college students, this issue is still worth exploring and discussing as college students, valuable talent resources, are closely related to the future of a nation and a people as well as the stability of society and families. Through our research, diverse characteristics of Chinese contemporary college students and the following countermeasures are raised: systematic psychological health education should be conducted among all college students, especially among those with suicide personality characteristics; medical and psychological treatment should be provided for those with mental diseases or depression; crisis intervention should be implemented among those who have suicide intentions or even have committed suicides. We hope these findings could provide some reference for our efforts to effectively prevent and intervene suicides among Chinese college students.

\section{References}

Chen, Zhixia. Zhu, Lilian. Li, Hongtao. (2004). On College Students' Suicide Intentions and Attitudes. Memoir for the Eighth Seminar on Psychological Health Education and Psychological Consultation in Chinese Universities.

Chu, Huiping. (2007). A Study on Life Education in University from the Perspective of College Students' Suicide. Jiangsu Higher Education. (1).

Cui, Liyong. (2006). College Students' Suicide and Psychological Health Education. Theory Journal. (5).

Guo, Baohua. Analysis and Countermeasures of College Students' Suicide. Journal of Northwestern Polytechnic University. 1. pp55-57.

Liu, Jiliang. Li, Han. (2000). On Life Education in Hong Kong. Jiangxi Education. (12): p28.

Lu, Qin. Li, Qu. Shao, Changyu. (2010). A Research on Grade 2009 Students' Psychological Health Conditions: A Case Study of a University in Chengdu. Education and Teaching Research. (3). p18.

Meng, Qingen. (2002). Precaution and Intervention of College Students' Suicide. Youth Study. (10).

Nordstrom P, Samuelssonm Asberg M. (1995). Suicide Analysis of Suicide Risk after Attempted Suicides. Acta Psychair Scand. 91(2).

Shen Jingjing. (2008). On the reason of College Students' Suicide. Forum on Contemporary Education. (5).

Wang, Di. (2009). A Summary on Causes for Chinese College Students' Suicide. China Youth Study. 11. pp 82-85.

Wang, Weihong. (2007). Depression, Suicide and Crisis Intervention. Chongqing Press. pp274-284.

Zhai, Shutao. (1997). Crisis intervention and Suicide prevention. People's Medical Publishing House Co. Ltd. p36. 